\title{
Effective Phages as Green Antimicrobial Agents Against Antibiotic-Resistant Hospital Escherichia coli
}

\author{
Rana Rahmani ${ }^{1}$; Gholamreza Zarrini $^{1,}$; Farzam Sheikhzadeh $^{2}$; Naser Aghamohammadzadeh $^{3}$ \\ ${ }^{1}$ Laboratory of Microbiology, Department of Biology, Faculty of Natural Sciences, University of Tabriz, Tabriz, IR Iran \\ ${ }^{2}$ Department of Animal Sciences, Faculty of Natural Sciences, University of Tabriz, Tabriz, IR Iran \\ ${ }^{3}$ Department of Medicine, Tabriz University of Medical Sciences, Tabriz, IR Iran \\ *Corresponding author: Gholamreza Zarrini, Laboratory of Microbiology, Department of Biology, Faculty of Natural Sciences, University of Tabriz, Tabriz, IR Iran. Tel: +98-4113392707, \\ Fax:+98-4113356027, E-mail: Zarrini@tabrizu.ac.ir
}

Received: January 20, 2014; Revised: May 3, 2014; Accepted: May 14, 2014

\begin{abstract}
Background: Bacteriophages are viruses that attack bacteria and lead to their lysis in an efficient and highly specific manner. These natural enemies of bacteria were used as therapeutic agents before the advent of antibiotics. Currently, with the rapid spread of multidrug resistant bacteria, phage therapy can be an effective alternative treatment for antibiotic resistant bacteria.

Objectives: This study evaluated the effectiveness of bacteriophages in removing antibiotic-resistant clinical Escherichia coli strains in vitro and in vivo.

Patients and Methods: Different samples were taken from bed sore and foot ulcers of patients with diabetes. E. coli strains were isolated and identified by standard methods. The antibiogram was ascertained using the Kirby Bauer disc diffusion method for ten antibiotics. The bacteriophages were isolated from environmental water samples. They were exposed to the host bacteria by the double-layer agar technique (DLA) to observe plaques. Cross reaction of the phages on test E. coli strains was performed to determine broader-spectrum phages. Phage TPR7 was selected for animal trials. Five groups of mice including a control group, bacterial group, phage group, antibiotic therapy group and phage therapy group, were examined.

Results: Ten E. coli strains were isolated from hospital samples. They showed high resistance to the used antibiotics. An effective bacteriophage was isolated for each strain. The cross-reaction showed phages which affect more than six E. coli strains. They can be a good choice for clinical therapeutic use. In animal trials the group challenged with phages after being infected showed similar results as the group treated with gentamicin after being infected. In both groups infection was removed after 48 hours.

Conclusions: According to the results, six strains were resistant to six or seven antibiotics and all strains were at least resistant to two antibiotics. However, for each of these resistant bacteria one bacteriophage was isolated from environmental samples, which showed the effectiveness of bacteriophages to remove clinically resistant $E$. coli strains. Effective phages in vitro showed effective results in vivo as well.
\end{abstract}

Keywords: Bacteriophage; Hospital; Antibiotic Resistant; Mice

\section{Background}

Bacteriophages are bacteria-specific viruses that infect and destroy their host bacteria. Bacteriophages are the most ubiquitous (total number estimated to be $10^{30}$ $10^{32}$ ) known organisms on Earth. They are found everywhere and their isolation is not expensive (1). Effective use of bacteriophages against bacteria was discovered by d'Herelle in 1915. In his studies he could observe clear plaques after treatment of bacteria with bacteriophages. Other researches have led to the therapeutic use of bacteriophages (2). However, with advances of antibiotics these natural enemies of bacteria were put aside. Today, with dissemination of multi-drug resistant (MDR) bacteria we need to find new remedies to overcome MDR pathogens. Developing new antibiotics with new modes of action is critical in the battle against antibiotic-resistant bacteria, yet this solution has had a slow and expensive pathway over the past years. For example during 1998 to 2003 only two antibiotics with new modes of action were approved by the Food and Drug Administration (FDA) (1).

Bacteriophages are accepted as natural antimicrobial agents to fight bacterial infections in humans, animals or crops of agricultural importance (3). Moreover, bacteriophages are easily accessed, cheap and safe for humans. On the other hand, resistance mechanisms to antibiotics and bacteriophages are different. Bacteria have different complex mechanisms against antibiotics, which are difficult to overcome; yet resistance to bacteriophages has not been commonly reported, and in case there is resistance, it will be via different mechanisms. This means that antibiotic resistant bacteria remain sensitive to bacteriophages. Thus they are the 
best choice for elimination of antibiotic resistant bacteria (1). However, it is important to mention that successful use of bacteriophages for therapeutic purposes in humans requires more research. For example FDA approved a phase I clinical trial in 2008 , which evaluated the safety of a phage cocktail to treat patients with infected venous leg ulcers (4). Escherichia coli is a Gramnegative pathogen that causes a variety of diseases and can be present in wounds such as bed sore and foot ulcers of patients with diabetes. Local infections such as wounds are the first choice for the therapeutic application of bacteriophages. This study was done to evaluate the effectiveness of bacteriophages in removing antibiotic-resistant E. coli.

\section{Objectives}

This study aimed to evaluate the effectiveness of isolated phages against isolated resistant $E$. coli strains. The phages with broader host range in vitro were used in vivo in a mice model.

\section{Patients and Methods}

\subsection{Bacteria Cultivation and Identification}

Different samples were collected from bed sore and foot ulcers of patients with diabetes. The samples were cultured on eosin-methylene blue (EMB) and blood agar media (Merck, Germany). The colonies were then purified and assessed by microscopic and culture methods and confirmed by standard biochemical tests such as the IMViC test.

\subsection{Antibiotic Susceptibility Test}

Antibiogram of all isolated E. coli were ascertained using the Kirby Bauer disc diffusion method against ten antibiotics. All plates were incubated for 18-24 hours at $37^{\circ} \mathrm{C}$ and zone of inhibition was measured for each disc according to the Clinical and Laboratory Standards Institute (CLSI) guidelines. Ten antimicrobial agents belonging to eight different groups including amoxicillin (AMX), gentamicin (GM), nalidixic acid (NA), tetracycline (TE), azithromycin (AZM), colistin (CL), kanamycin (K), ciprofloxacin (CP), doxycycline (D), and cephalexin (CN) were used. All the test antibiotic discs were purchased from Padtan Teb Co.

\subsection{Isolation and Purification of Bacteriophages for Clinical E. coli}

The bacteriophages were isolated from environmental water samples. Some domestic wastewater and creek waters that flow in streets of Tabriz such as "AjiChay" river were used for sampling. After collecting $100 \mathrm{~mL}$ of water in sterile bottles, water samples were amplified by adding $50 \mathrm{~mL}$ of tryptic soy broth media (Merck, Germany) and inoculating host bacteria (5). These water samples were incubated overnight at $37^{\circ} \mathrm{C}$, followed by centrifugation after addition of chloroform. The supernatants were extracted as probable bacteriophage samples. The supernatants were exposed to the host bacteria by the double-layer agar method (6). After overnight incubation at $37^{\circ} \mathrm{C}$, plates were analyzed to observe plaques. Single plaques were separated and repeated culture in double-layer agar plates were done to extract single bacteriophages. Isolated bacteriophages were stored in SM buffer at $4^{\circ} \mathrm{C}$.

\subsection{Cross-Reactivity}

In addition to the host microorganism used for isolation of each bacteriophage, activity of each bacteriophage against the other nine E. coli was examined by the double-layer agar method to determine potent broader-spectrum bacteriophages for therapeutic application.

\subsection{Bacteriophage Titration}

For counting bacteriophages, dilutions were prepared by adding $900 \mu \mathrm{L}$ of sterile water to each $100 \mu \mathrm{L}$ of phage samples. Each dilution was cultured by the double layer method. At high dilutions whole surface of plates were lysed by bacteriophages. At lower dilutions, plaques were countable. The titer of a phage suspension was determined by counting the number of plaques that formed from a given volume of suspension, based on the fact that each plaque on a lawn of bacteria contains $10^{6}$ to $10^{7}$ phages (5).

\subsection{Animals}

Thirty-five mice (25 - 30 gram each) were purchased from the faculty of new sciences of Tabriz University of Medical Sciences. They were randomly divided to five groups. A full thickness skin wound was made, by a surgical tool, on the mice's backs between their two ears. Group 1, which was the control group (C), did not receive anything. Group 2, the bacterial group (B), received E. coli M6 at a dose of $1.5 \times 10^{9} \mathrm{CFU} / \mathrm{mL}$. Group 3, the phage group $(\mathrm{P})$, received only phage at a dose of $10^{10} \mathrm{PFU} / \mathrm{mL}$. Group 4, the antibiotic therapy group (BA), received E. coli M6 at a dose of $1.5 \times 10^{9} \mathrm{CFU} / \mathrm{mL}$, and was treated by gentamicin after 24 hours and a repeated dose after 48 and 72 hours. Group 5, the phage therapy group (BP), received E. coli M6 at a dose of $1.5 \times 10^{9} \mathrm{CFU} /$ $\mathrm{mL}$ and after 24 hours, topically received a single dose of bacteriophage TPR7 with a dose of $10^{10} \mathrm{PFU} / \mathrm{mL}$. Wound sampling was performed by a sterile swap every day after applying bacteria to the wound, and samples were cultured on EMB. After incubating for 24 hours, colonies were counted.

\section{Results}

In this study ten E. coli strains were successfully isolated 
Rahmani Retal.

Table 1. Antibiotic Resistant Patterns for the Clinical Escherichia coli Isolates a

\begin{tabular}{lcccccccccc}
\hline & E. coli M1 & E. coli M2 & E.coli M3 & E. coli M4 & E. coli M5 & E.coli M6 & E. coli M7 & E.coli M8 & E.coli M9 & E.coli M10 \\
\hline Amoxicillin & $\mathrm{R}$ & $\mathrm{R}$ & $\mathrm{R}$ & $\mathrm{R}$ & $\mathrm{R}$ & $\mathrm{R}$ & $\mathrm{R}$ & $\mathrm{R}$ & $\mathrm{R}$ & $\mathrm{R}$ \\
Azithromycin & $\mathrm{R}$ & $\mathrm{R}$ & $\mathrm{R}$ & $\mathrm{R}$ & $\mathrm{R}$ & $\mathrm{R}$ & $\mathrm{R}$ & $\mathrm{R}$ & $\mathrm{R}$ & $\mathrm{R}$ \\
Cephalexin & $\mathrm{R}$ & $\mathrm{S}$ & $\mathrm{R}$ & $\mathrm{S}$ & $\mathrm{R}$ & $\mathrm{R}$ & $\mathrm{R}$ & $\mathrm{R}$ & $\mathrm{R}$ & $\mathrm{S}$ \\
Nalidixic Acid & $\mathrm{R}$ & $\mathrm{R}$ & $\mathrm{R}$ & $\mathrm{S}$ & $\mathrm{R}$ & $\mathrm{S}$ & $\mathrm{R}$ & $\mathrm{R}$ & $\mathrm{R}$ & $\mathrm{S}$ \\
Doxycycline & $\mathrm{R}$ & $\mathrm{R}$ & $\mathrm{S}$ & $\mathrm{S}$ & $\mathrm{I}$ & $\mathrm{S}$ & $\mathrm{R}$ & $\mathrm{S}$ & $\mathrm{R}$ & $\mathrm{S}$ \\
Tetracycline & $\mathrm{R}$ & $\mathrm{R}$ & $\mathrm{S}$ & $\mathrm{S}$ & $\mathrm{R}$ & $\mathrm{S}$ & $\mathrm{R}$ & $\mathrm{S}$ & $\mathrm{R}$ & $\mathrm{S}$ \\
Ciprofloxacin & $\mathrm{R}$ & $\mathrm{S}$ & $\mathrm{R}$ & $\mathrm{S}$ & $\mathrm{R}$ & $\mathrm{S}$ & $\mathrm{S}$ & $\mathrm{S}$ & $\mathrm{S}$ & $\mathrm{S}$ \\
Gentamicin & $\mathrm{S}$ & $\mathrm{S}$ & $\mathrm{R}$ & $\mathrm{S}$ & $\mathrm{S}$ & $\mathrm{S}$ & $\mathrm{R}$ & $\mathrm{S}$ & $\mathrm{S}$ & $\mathrm{S}$ \\
Kanamycin & $\mathrm{S}$ & $\mathrm{R}$ & $\mathrm{I}$ & $\mathrm{S}$ & $\mathrm{R}$ & $\mathrm{S}$ & $\mathrm{S}$ & $\mathrm{S}$ & $\mathrm{S}$ & $\mathrm{S}$ \\
Colistin & $\mathrm{S}$ & $\mathrm{S}$ & $\mathrm{S}$ & $\mathrm{S}$ & $\mathrm{S}$ & $\mathrm{S}$ & $\mathrm{S}$ & $\mathrm{S}$ & $\mathrm{S}$ & $\mathrm{S}$ \\
\hline
\end{tabular}

${ }^{\mathrm{a}}$ Abbreviations: I, intermediate; $\mathrm{R}$, resistant; $\mathrm{S}$, sensitive.

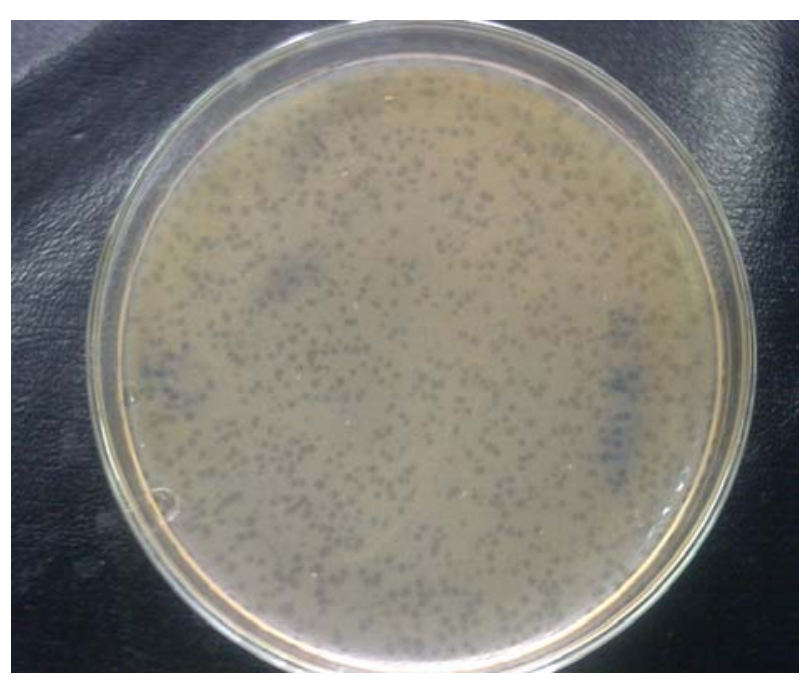

Figure 1. Bacteriophage TPR6 Plaques on E. coli M6

from the clinical samples. They were called E. coli M1 to E. coli M10. Study of antibiotic resistance patterns showed high levels of resistance in E. coli isolates. The results showed that all strains were resistant to at least two antibiotics and six strains were resistant to six or seven antibiotics, indicating high levels of resistance. All strains were resistant to amoxicillin and azithromycin, yet sensitive to colistin. Except for two strains, the others were sensitive to gentamicin and kanamycin. Three strains were resistant to ciprofloxacin and five were re- sistant to tetracycline and doxycycline. Seven strains showed resistance to cephalexin and nalidixic acid. Table 1 illustrates the entire resistance patterns to antibiotics. At least one bacteriophage was isolated against each E. coli strain. They were called TPR1 to TPR10. Each of the bacteriophages lysed its host completely (Figure 1). However, examination of their activity on other E. coli strains showed that each $E$. coli was sensitive to at least two phages in addition to its own specific phage (Table 2). The phage, TPR10, was effective against seven E. coli strains. Six E. coli strains were sensitive to TPR5 and TPR6. The phage, TPR4, was effective against half of the bacteria. Four bacteria were sensitive to TPR1, TPR8 and TPR9 while three of bacteria were sensitive to TPR2, TPR3 and TPR7. Furthermore, TPR10, TPR5 and TPR6 had broader host ranges and could be a good choice for phage therapy in clinical use for multiple infections. Comparison of the effectiveness of antibiotics and isolated bacteriophages on isolated bacteria is shown in Table 3. The TPR7 isolate was selected to remove E. coli M6 in vivo because of its big and clear plaques. The other nine phages had different plaques according to size; some big and very small. Four mice in group $\mathrm{B}$ died on the third day. However, the other three mice were still infected by bacteria until the seventh day and they received serum because they were moribund. In group BA, there were no bacteria in their samples after the second day. Surprisingly in group BP results were similar to group BA, and there were no bacteria in their samples after the second day. The results of the sampling of the five groups are showed in Figure 2. A single dose of phage could remove infection, while repeated doses of antibiotic were required for infection removal. 
Rahmani Ret al.

\begin{tabular}{|c|c|c|c|c|c|c|c|c|c|c|}
\hline & E. coli $\mathbf{M 1}$ & E. coli $\mathbf{M} 2$ & E. coli $\mathbf{M} 3$ & E. coli $\mathbf{M} \mathbf{4}$ & E. coli M5 & E. coli M6 & E. coli $\mathbf{M} 7$ & E. coli $\mathbf{M 8}$ & E. coli M9 & E. coli M10 \\
\hline TPR1 & + & - & + & - & + & - & - & - & + & - \\
\hline TPR2 & - & + & + & - & - & + & - & - & - & - \\
\hline TPR3 & + & - & + & - & - & + & - & - & + & - \\
\hline TPR4 & - & - & - & + & + & - & + & + & + & - \\
\hline TPR5 & - & + & + & + & + & + & - & - & - & + \\
\hline TPR6 & - & - & + & - & + & + & + & + & + & - \\
\hline TPR7 & + & - & - & - & - & + & + & - & - & - \\
\hline TPR8 & + & - & - & - & - & - & + & + & + & - \\
\hline TPR9 & + & - & - & - & - & + & - & - & + & + \\
\hline TPR10 & + & + & - & + & - & + & + & - & + & + \\
\hline
\end{tabular}

Table 3. Resistance of Isolated E. coli Strains to Antibiotics and Susceptibility to Bacteriophages

\begin{tabular}{lcccccccccc}
\hline & E. coli $\mathbf{M 1}$ & E. coli $\mathbf{M 2}$ & E. coli M3 & E. coli M4 & E. coli M5 & E. coli M6 & E. coli M7 & E. coli M8 & E. coli M9 & E. coli M10 \\
\hline $\begin{array}{l}\text { Antibiotic } \\
\text { resistant }\end{array}$ & 7 & 6 & 6 & 2 & 7 & 3 & 7 & 4 & 6 & 2 \\
$\begin{array}{l}\text { Phage } \\
\text { sensitive }\end{array}$ & 6 & 3 & 5 & 3 & 4 & 6 & 5 & 4 & 6 & 3 \\
\hline
\end{tabular}

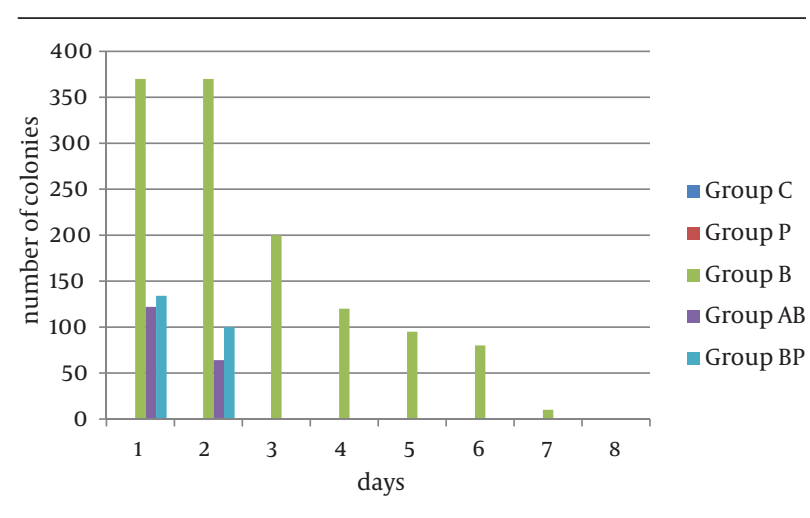

Figure 2. Number of Colonies in Five Groups

\section{Discussion}

Antibiotic resistant bacteria are increasingly found in different bacterial infections. Among bacterial infections, E. coli is present in many cases. Researches have shown high resistance to antibiotics by this bacterium. Momoh et al. (7) studied the antibiogram types of E. coli isolated from suspected urinary tract infection samples and reported high resistance to the used antibiotics. Mubita et al. studied $83 \mathrm{E}$. coli isolates from cattle. They reported a high frequency of $E$. coli resistance to multiple antibiotics such as penicillin, erythromycin, co-trimoxazole and nitrofurantoin (8). Thaker et al. (9) studied antibiogram patterns of $E$. coli from raw milk samples and reported resistance to ampicillin, streptomycin, oxytetracycline and co-amoxiclav. Before the antibiotic era, some studies reported effective use of bacteriophages as an antimicro- bial agent in animals and even in humans. Smith et al. (10) successfully treated experimental E. coli infections in mice using phages. They also controlled experimental $E$. coli diarrhea in calves by means of bacteriophages. Their phage isolates effectively controlled the multiplication of that particular strain of E. coli in the small intestines of calves (11).

Barrow et al. (12) successfully used lytic bacteriophage for the control of experimental E. colisepticemia and meningitis in chickens and calves. Jamalludeen et al. (13) evaluated bacteriophages for prevention and treatment of diarrhea due to experimental enterotoxigenic E. coli O149 infection in pigs. Their selected phages were effective in moderating the course of experimental O149:H10:F4 Enterotoxigenic Escherichia coli (ETEC) diarrhea in weaned pigs when given prophylactically or therapeutically. Other similar studies have been done in the past. However, with the emergence of antibiotics such research became rare. New studies for an alternative to antibiotics aimed to find methods for generation of bacteriophage cocktails with therapeutic potential, such as the research by $\mathrm{Gu}$ et al. (14). A safety test of phage therapy was done in 2005 , in which healthy human volunteers received $E$. coli bacteriophage T4 orally and the results showed safety of bacteriophages (15). Our research supported past studies and showed that bacteriophages could be isolated and used effectively against antibiotic resistant clinical E. coli strains to remove these bacteria. Our research results showed different patterns of resistance to antibiotics and bacteriophages by bacteria.

The most resistant E. coli strains were resistant to seven antibiotics. However, E. coli M1, E. coli M5 and E. coli M7 were sensitive to six, four and five bacteriophages re- 
spectively. E. coli M4 and E. coli M10 which were the most sensitive bacteria to antibiotics were sensitive to three different bacteriophages. As the results show (Table 3), the resistance pattern was different to antibiotics and bacteriophages. This maybe because the mechanisms of resistance against bacteriophages are different from those for resistance to antibiotics (3). According to the results of this research, all ten isolated E. coli strains, which were resistant to several antibiotics, could be eliminated by bacteriophages, which are easily isolated from environmental water samples without the need for expensive procedures. Similar therapeutic effects of phages to antibiotics in vivo prove the fact that phages can be good alternatives for antibiotics to cure resistant infections.

\section{Acknowledgements}

This work was part of an MSc thesis from University of Tabriz. The authors appreciate the Emam Reza and Sina Hospital's staff for collecting the bacterial samples.

\section{Authors' Contributions}

Gholamreza Zarrini and Farzam Sheikhzadeh developed the original idea and the protocol. Naser Aghamohammadzadeh contributed to the isolation of bacterial strains and Rana Rahmani contributed to the experimental work.

\section{Funding/Support}

This study was supported by the University of Tabriz, Iran.

\section{References}

1. Sulakvelidze A. The challenges of bacteriophage therapy. Eur Ind Pharm. 2011;10:14-8.

2. Abhilash M, Vidya A, Jagadevi T. Bacteriophage therapy: A war against antibiotic resistant bacteria. Internet $J$ Altern Med. 2009;7(1),e 13668.

3. Ghannad MS, Mohammadi A. Bacteriophage: time to re-evaluate the potential of phage therapy as a promising agent to control multidrug-resistant bacteria. Iran J Basic Med Sci. 2012;15(2):693.

4. Rhoads DD, Wolcott RD, Kuskowski MA, Wolcott BM, Ward LS, Sulakvelidze A. Bacteriophage therapy of venous leg ulcers in humans: results of a phase I safety trial. J Wound Care. 2009;18(6):237-8.

5. Alexander SK, Strete D, Niles MJ. Laboratory exercises in organismal and molecular microbiology:: McGraw-Hill; 2004.

6. Pattee PA. Use of tetrazolium for improved resolution of bacteriophage plaques. J Bacteriol. 1966;92(3):787-8.

7. Momoh ARM, Orhue PO, Idonije OB, Oaikhena AG, Nwoke EO, Momoh AA. The antibiogram types of Escherichia coli isolated from suspected urinary tract infection samples. J Microbiol Biotech Res. 2011;1(3):57-65.

8. Mubita C, Syakalima M, Chisenga C, Munyeme M, Bwalya M, Chifumpa G, et al. Antibiograms of faecal Escherichia coli and Enterococci species isolated from pastoralist cattle in the interface areas of the Kafue basin in Zambia. Vet Arh. 2008;78(2):179.

9. Thaker H, Brahmbhatt M, Nayak J. Study on occurrence and antibiogram pattern of Escherichia coli from raw milk samples in Anand, Gujarat, India. Vet World. 2012;5(9):556.

10. Smith HW, Huggins MB. Successful treatment of experimental Escherichia coli infections in mice using phage: its general superiority over antibiotics. J Gen Microbiol. 1982;128(2):307-18.

11. Smith HW, Huggins MB, Shaw KM. The control of experimental Escherichia coli diarrhoea in calves by means of bacteriophages. J Gen Microbiol. 1987;133(5):1111-26.

12. Barrow P, Lovell M, Berchieri A Jr. Use of lytic bacteriophage for control of experimental Escherichia coli septicemia and meningitis in chickens and calves. Clin Diagn Lab Immunol. 1998;5(3):294-8.

13. Jamalludeen N, Johnson RP, Shewen PE, Gyles CL. Evaluation of bacteriophages for prevention and treatment of diarrhea due to experimental enterotoxigenic Escherichia coli O149 infection of pigs. Vet Microbiol. 2009;136(1-2):135-41.

14. Gu J, Liu X, Li Y, Han W, Lei L, Yang Y, et al. A method for generation phage cocktail with great therapeutic potential. PLoS One. 2012;7(3).

15. Bruttin A, Brussow H. Human volunteers receiving Escherichia coli phage T4 orally: a safety test of phage therapy. Antimicrob Agents Chemother. 2005;49(7):2874-8. 